\title{
Analyzing a Cross-cultural Communication Framework From the Perspective of Relational Rationality: A Case Study of Chinese Confucius Institute in the Last Decade*
}

\author{
Ya YANG \\ Beijing Normal University, Beijing, China
}

\begin{abstract}
In this study, we discuss the role of "relational rationality" and the multi-dimensions in interpreting ongoing cross-cultural communication between China and the world. The concept of relational rationality is in search of the best community instead of an exclusive communication. Thus, from this relationological point of view, we have to re-build the framework of cross-cultural communication on the basis of coexistence rather than of closed existence. It is correlations that determine the existential situation and values of communication in the current world. Therefore, cross-cultural communication could not only recognize the pattern of one culture, but also provide the possibility of the cultural formation of common sense. In order to establish the framework, we need to understand the exogenous multi-dimensional elements including politics, economy, culture and so on, as well as the interrelationship among those elements; at the same time, we also need to study the endogenous process of cross-cultural communication on the micro level, including the senders, channels and receivers. As a result, we illustrate the cross-cultural framework with an empirical case study of the 5,932 news of Chinese Confucius Institute within 1,246 main websites in more than a hundred countries or districts from 2004 to 2015 .
\end{abstract}

Keywords: cross-cultural communication, Confucius Institute, relational rationality

\section{Introduction}

Cross-cultural communication pervades all behaviors in human society and promotes change and development of society. With the absence of cross cultural communication, there could be no more evolution of human civilization. As British philosopher Bertrand Russell pointed out, "the exchange of civilizations is the milestone in the development of human civilization". It is cross-cultural communication that connects people from different regions, races, and nationalities. With the rapid development of transportation and ICTs, cross-cultural communication is no longer a rarity for us. If communication is a way of human life, cross-cultural communication is a way of life for people in a "world community" called the global village.

The Chinese Confucius Institute is a main organization undertaking the role of fostering cross-cultural communication, similarly to the goals of the Spanish Cervantes Institute and the German Goethe Institute, in the sphere of language and culture. From 2004 to 2015, 495 Confucius Institutes and 1,000 Confucius courses

\footnotetext{
*Acknowledgements: The author would like to appreciate the support of General Financial Grant from the China Postdoctoral Science Foundation funded project (Grant No. 2016M600057) and Chinese Hanban, and also give sincere thanks to Pu CAO in Renmin University of China for the help of coding and analyzing. Ya YANG, Postdoctoral Scholar, School of Journalism and Communication, Beijing Normal University.
} 
have been set up in over a hundred countries or regions. The development of the Confucius Institute has shown its diversified and specialized tend, including a series of institutes and courses that focus on areas such as traditional Chinese medicine, agriculture, music, textile and garment, which in turn promote the spread of language learning (AN \& WEI, 2015). Presently, in terms of cross-cultural communication, the Confucius Institute is also encountering obstacles in carrying out their mission, such as the existence of a lack of dimension in ways of communication, vague evaluation systems, and an absence of innovation in brands and ideas (Blue Book, 2016). This has created criticism of questionable qualifications of teaching staff and hindering of academic freedom (New York Times, 2012).

\section{Literature Review}

\section{Confucius Institute and Cross-cultural Communication}

Most existing frameworks of cross-cultural communication of the Confucius Institute are organized around three aspects: education, soft power, and economic globalization.

The education aspect of the study is split in two levels. In the first, the micro level, the aspect of research focuses on educating and teaching from the fields of literature and linguistics and education management. Case studies and questionnaires are applied in studying curriculum, textbooks, teachers and teaching methods (WU, 2012). The second level is the meso level. The research areas of this level are concentrated in the fields of education management and cross-cultural communication. Through quantitative and qualitative research methods and by comparing data with other countries and similar institutions, such as the Cervantes Institute and the Goethe Institute, the main purpose of this level of research is to analyze the functioning and management model of the institute. For instance, there are three modes of management: industrial management, funding and donation, and Hanban project (WU, 2011).

The research aspect of cross cultural communication and soft power contains a few important articles. In 2009, a series of articles published in the European Journal of Education discussed that China and the EU have entered into a new era of cultural contacts and pedagogical cooperation. The Confucius Institute has experienced a rapid development in continental Europe. Starr (2009) analyzed the relationships between the Confucius Institute, public diplomacy and soft power. Some scholars also believed that the Confucius Institute is the external projection of good Chinese international image (Paradise, 2009; Pan, 2013), while some proposed a concern about the "troy effect" occurring among western scholars (Paradise, 2009) and still hold the view that the Confucius Institute is part of China's official cultural institutions (Hartig, 2012).

It is worth mentioning that LIEN (2011) initially studied the Confucius Institute from the perspective of economic globalization and discussed the relationship between the spread of the Confucius Institute and macroeconomic variables, such as export trade and foreign direct investment; then, he verified the correlation between the Confucius Institute development and foreigners working and travelling in China and thus proved the positive external effect of the Confucius Institute (LIEN, 2013).

\section{Relational Rationality}

The concept of relational rationality pervades modern research, including physiological, sociological, potential science and institutional approaches (MA \& LIU, 2016; Aronsson \& Hundeide, 2002; Van Campenhoudt, 1999). Relational rationality is in search of the best "community" instead of an exclusive community. Thus, from this relationological point of view, we have to re-build the framework of cross-cultural 
communication on the basis of coexistence rather than on one of a closed existence. It presents correlations that determine the existential situation and values of communication in the current world.

To put forward what Castel referred to the "new rational order that is simpler and more consistent than the others to explain the real behaviors of social agents" (Van Campenhoudt, 1999), the new rationality cannot be "objective rationality" based on an abstract "community", or "subjective rationality" relying on "abstract individuals"; instead, it should be "relational rationality" that transcends both (HE, 2015). By focusing on relationships rather than senders/receivers concerned, community could be built and uncertainty reduced. The problem is the "unidimensionality" (Ettlinger, 2003) of current conditions. Therefore, building a theoretical framework that relatively stably integrates and structures all the factors influencing cross-cultural communication is useful. The framework should contain two essential points: (1) relational rationality, and (2) world real community.

\section{Data Collection}

Related news data in a foreign language from "Access World News" and data in Chinese from "Huike Library of Chinese Newspapers and Periodicals" were collected. After de-duplication and removing content unrelated to the Confucius Institute (like "Confucius" and "Confucianism"), we illustrate the cross-cultural framework with an empirical case study of the 5,932 news articles about the Chinese Confucius Institute found on 1,246 main websites in more than a hundred countries or districts from 2004 to 2015, including 3,193 news stories in English and 1,111 news stories in Chinese.

\section{Coding}

To illustrate our coding method, take coding of English news as an example. "Year of the reports" was coded within 2004 to 2015. "Continents" were coded in five categories: Asia, North America, South America, Europe, and Oceania. "Countries or regions" were coded as Australia, Canada, the United States, Japan, Hong Kong, Britain, Korea, and France. "Media type" was coded in five categories: newspapers, websites, television, broadcasts, and news agencies. "Media ranking" was coded as national, local, industrial level, and personal website. "Media properties" were coded as public media, commercial media, and state media. "News genre" was coded with four categories: news, comments, features, advertising, others. Reporting topics covered politics, economy, culture, society, education, others. Reporting tendencies are divided into positive, neutral, and negative.

\section{Findings}

RQ 1: Which part of world concerns itself most with the Confucius Institute?

The study analyzed five continents and found that the largest proportion of news reports, both in English and Chinese, lie in North America with a proportion of $46 \%$ of coverage. Of all the countries, reports in the United States accounted for $42.5 \%$ of the total news, followed by reports from Britain (16.03\%), Australia (14.1\%), and France (9.29\%). From the media level perspective, news from national media accounted for $94.87 \%$, and a minority of the English language news covered on local media, with a frequency of $5.13 \%$, which suggests that the countries that reported related issues place a higher degree of emphasis on the Confucius Institute.

When reporting international news, the media always tends to "domesticate" the news, which is emphasizing the relevance and closeness of the international news to its own audience. Based on our interview 
with several foreign reporters at the Beijing correspondent station, we drew a similar analysis. It was a Chinese issue reporter in our interview said, "Americans do not pay much attention to the affairs outside United States, but as long as the international affairs concern China, people will, to a great extent, pay attention to it". Thus every time the reporter wrote an article with "Beijing" in the news lead, he knew the story would be seen by several people.

In the process of fostering cross-cultural communication, various factors lead to the decoding of recipients, which is often different from the encoding of the sender, so that the communication intention and expected effect of the sender cannot be realized. We cannot say this is not related to the status quo of the Sino-US relationship in recent years. Media and audiences in western world exist mostly in a "single-minded" line of thinking. People will inevitably have some deep-rooted stereotypes of countries that belong to another culture circle. In the case of China, its stereotype lies in considering China as a "rising threatening power". This situation leads the American reporter to shape and interpret the image of the Chinese Confucius Institute from an ideological angle of power relationships and also leads the common audience to accept these news reports based on their existing "subjective" framework.

Journalists reporting on Chinese affairs are a very complex and diverse group. In the coverage of the Confucius Institute report, the category of media focused on original foreign media and the Chinese versions of foreign media present the respective proportions of $48.40 \%$ and $46.79 \%$. According to our interview with foreign reporters at the Beijing correspondent station, there are at least two kinds of foreign media journalists covering Chinese issues: one has learned and can understand Chinese or has lived in China for years, speaking and/or writing fluent Chinese; the other does not understand Chinese, and merely observes Chinese issues with a reporter's occupational sensitivity.

Reporters with the advantage of language usually can find unique topics or angles, obtain more first-hand information, and have a better understanding of Chinese issues. They can supply more background information or context in their articles and see more through the lens of a Chinese perspective. Reporters who lack these language skills observe and understand Chinese through translation. They mentioned that they often rely on English media to find topics, that is to say, they are more likely to have their agenda set by other media, including Chinese media like "China Daily" and also the international issues of other mainstream media. Therefore, although foreign media journalists define their role as "interpreters" and "explainers", they inevitably carry their own characteristics, which are marked by their cultural and language background, personal experiences and values, and inevitably create individual differences in their coverage of Confucius Institute issues.

RQ2: Are the reports concerning Confucius Institute positive or negative?

The study found that among all the media in our collection, media with no obvious bias accounted for $91.03 \%$. The media with left wing intentions (geared towards liberal, democratic, big government audiences and ideas) are slightly more frequent than that of the right (for conservative, Republican, small government audiences), with a frequency of $6.73 \%$ and $2.24 \%$ respectively. Thus, in general, these non biased media are able to restore the image of the Confucius Institute overseas. While, through correlation tests, we found that there is no significant correlation between the intentional position of media and their reporting tendency.

As far as the reporting tendency is concerned, media reports with a neutral tendency account for $57.37 \%$, which is also consistent with the aforementioned media itself lying in the neutral and objective position. 
However, negative reports are more frequent than positive reports, with negative reporting carrying a frequency of $28.53 \%$, while positive is only $14.10 \%$.

Take US news report for instance. Mainstream media in the United States are dominated by neutral reporting (55.88\%), while commercial websites $(54.55 \%)$ and foreign media in Chinese sources $(59.78 \%)$ are dominated by negative reports. In negative reports, the foreign media reports in Chinese versions account for the largest amount and the mainstream websites in America account for the least. In the neutral reports, the majority of American mainstream media reports account for the most; in the positive reports, the number of commercial websites account for the largest (see Figure 1).

\section{$=\odot=$ " main stream media $=0$ commercial websit $\quad \odot$ foreign media in Chinese version}

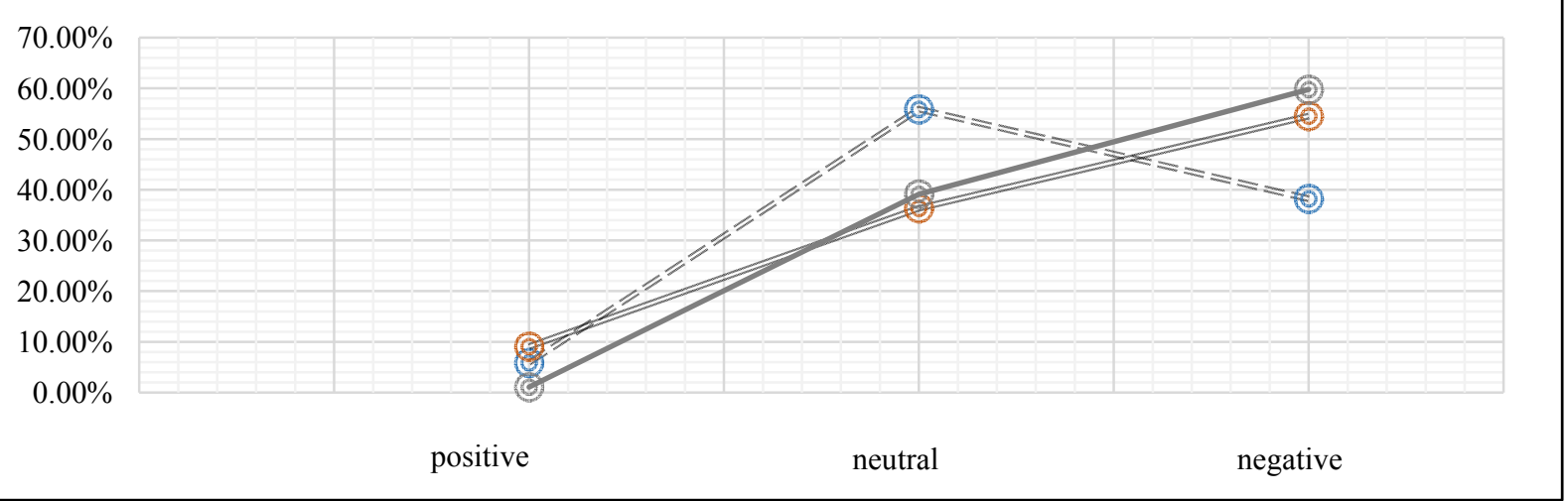

Figure 1. The correlation between media types and tendency in US.

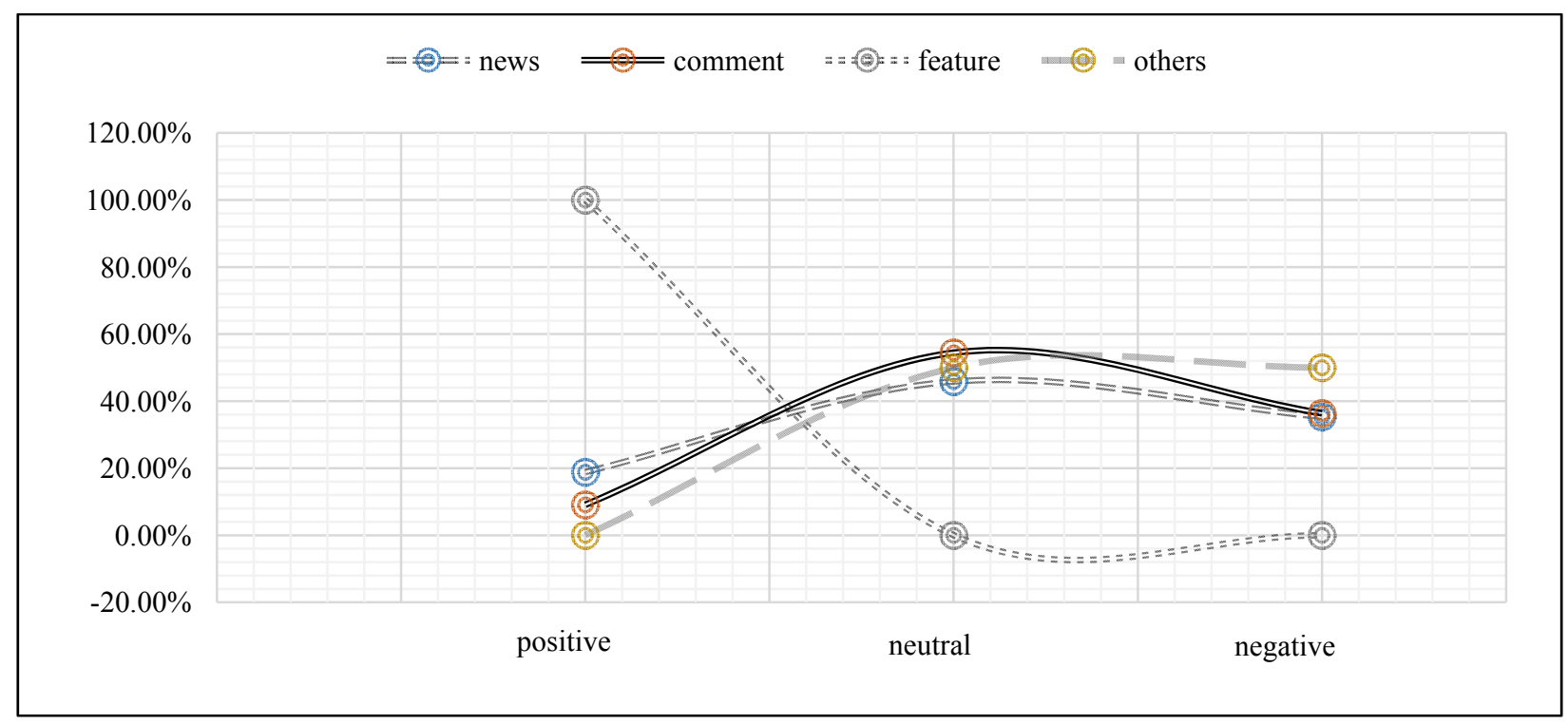

Figure 2. The correlation between reporting styles and tendency in US

As for reporting styles, the distributions of tendency are quite different. Despite the fact that the almost half of the news $(45.88 \%)$ and comments $(54.55 \%)$ are in neutral tendency, in comment styles, negative reports 
(36.36\%) are about four times more frequent than positive reports $(9.09 \%)$; while in news styles, the multiple number is twice, with the frequency of $35.29 \%$ and $18.92 \%$ representatively. It is noted that the Confucius Institute image is more negative in critical reviews (see Figure 2).

RQ3: Are the reports concerning the Confucius Institute interlined with other social spheres?

The concerns and behaviors of an institute might be intertwined with logics and rationalities from spheres of politics, economics, and culture. This does not refer to the fuzziness or disappearance of boundaries (Pratt, 1999). As shown in Figure 3, when the Confucius Institute's news are linked to different topics, the reporting tendencies can be quite different. When the Confucius Institute's news output was related to political themes, negative reports accounted for more than half (56\%). Among all six themes, including politics, economy, society, culture, education and others, the positive reports (33\%) were higher than negative reports (23\%) only when the Institute had been associated with culture themes. Economic, social, educational and other themes contain the most neutral reports. In the educational theme, the amount of negative reports $(25 \%)$ and positive reports $(21 \%)$ were approximately similar. This shows that the political, economic, social and educational influences of Confucius Institute are questioned by foreign media in varying degrees. Therefore, as far as news genre concerned, "Confucius Institute plus Politics" is the most negative, and "Confucius Institute plus Culture" the most positive.

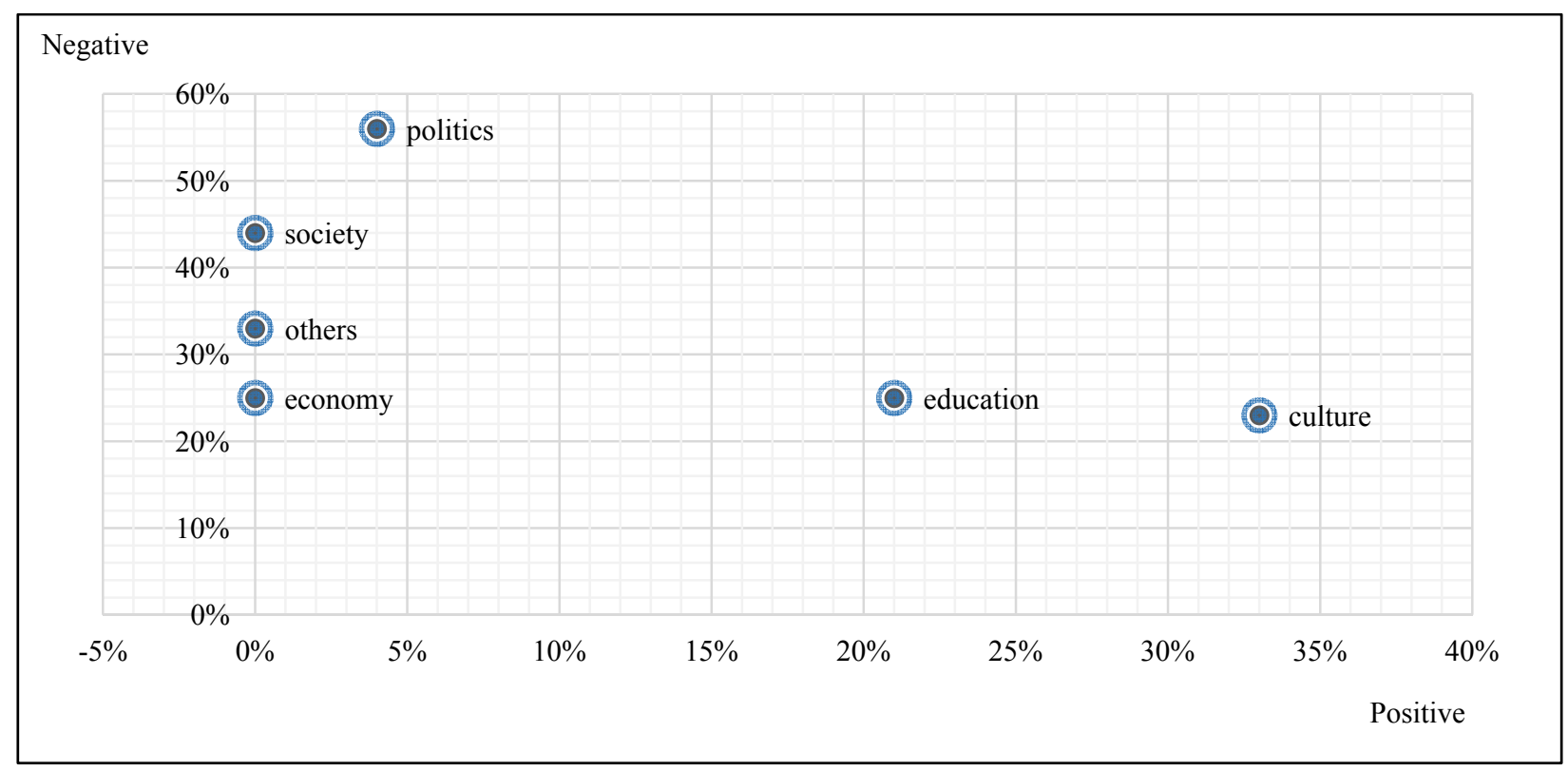

Figure 3. The correlation between news genre and tendency in US.

As Wilbur Schramm pointed out, "both the senders and the recipients create and understand information in the context of their personal experience. Thus, the more experiences shared by both sides, and the more closely each experience field overlaps, the better they would understand each other". Using OLS regression model, GUAN (2012) tested the influence of different social sphere variables on the distribution of the Confucius Institute. He determined three factors: (1) Culture and interest. With more foreign students studying in China, more Confucius Institutes would be possible to set up in foreign countries; (2) Economic assumption. With a larger volume of import and export of a country or region with China, it will intend to set up more Confucius Institute; (3) History and diplomatic relationship. With a longer history of formal diplomatic relations, the 
country will be more likely to set up Confucius Institutes. Therefore, the main factors contributing to the positive attitude towards the Confucius Institute are cultural, economic and political factors, which also intertwine with each other.

Besides, nowadays "mediation" is a meta process accompanied by globalization, namely, new media technology and the different forms of intermediary communication that go along with it. The logic of the media, as a mediation of meaning transmission and meaning construction, has a particularly prominent impact on other social factors. The logic of media is increasingly used as a form and strategy for observing the world, constructing our existences, and developing our actions and interactions. The social interactions mediated by the media and its reproduction has led to the identification of "community" and cultural identity beyond human direct perceptions of time and space.

\section{Discussion}

The contradiction between subjective rationality and the sense of community is the profound antinomy. From a relationological point of view, the world is a transcendental existence and the world itself should be the main subject (ZHAO, 2015). Relational rationality can lead to optimal relationships rather than optimal unilateral policies. This means that minimizing hurt is a priority, which is then followed by a pursuit to maximize one's own interests. More importantly, relational rationality acts as an intermediary in expanding dialogue between power and Internet freedom. Therefore, cross-cultural communication could not only recognize the pattern of one culture, but also provide the possibility of cultural formation of common sense.

Therefore, this study brought up a framework called "culture for the whole, real community" within cross-cultural communication. This concept is quite similar to the "basic supply of culture" (Dong, 2011), the keyword of German cultural industrial policy in the past few years. In such a framework, internationally recognized top cultural achievements and common mass cultural activities interact and complement each other. The "basic supply of culture" clears the standards of cross-cultural communication in three areas: firstly, culture and language depend on an environment of free development and are in need of adequate support and promotion; secondly, culture and education should ensure full coverage for the entire community; thirdly, cultural heritage of a nation must be protected and actively promoted to the public.

Within cross-cultural communication, the image of a country refers to the overall understanding and grasp of its international community, which is a complex of subjective perception from international community towards the objective formation. Therefore, national image is more focused on subjective evaluations and impressions. If cross-cultural communication was considered as a "scalar", it cannot distinguish between the subject and the object of communication, thus the effect of communication is greatly reduced. In terms of relational rationality, cross cultural communication is a "vector" defined by a direction as well as a magnitude, with a clear orientation from subject to object, which overcomes the shortcomings of the existing paradigm.

Opening the channel between oneself and others and providing both the recognition of individual culture and the possibility of creating a common sense of culture, this new rational state is so called "relational rationality". In the process of cross communication, we should set up a community that transcends objective reason and subjective reason and regards community vision as the basic dimension of cross culture communication. Heidegger once said, "the abolition of all distance does not bring about any closeness, for closeness does not consist in shortening distance". Then, if closeness lies not in the distance, where could it stand? In the tangled dialogue between structure and process, communication and interest, fact and value. The 
cross-cultural communication of the Confucius Institutes and the national image should also be interpreted from this perspective.

\section{References}

AN, R., \& WEI, X. (2015). Research on cross cultural communication model of Confucius Institute. International Communications, 1, 53-55.

Aronsson, K., \& Hundeide, K. (2002). Relational rationality and children's interview responses. Human Development, 45(3), 174-186.

Blue Book. (2016). Cultural Construction Report on Chinese Cultural Development (2015-2016). Retrieved from http://www.pishu.cn/zxzx/mtjj/377318.shtml

Dong, L. (2011). Confucius Institute and Goethe Institute: Cross cultural communication under different ideas. Journal of University of International Relations, 4, 76-79.

Ettlinger, N. (2003). Cultural economic geography and a relational and microspace approach to trusts, rationalities, networks and change in collaborative workplaces. Journal of Economic Geography, 3(2), 145-171.

GUAN, B. (2012). National soft power, Chinese learning boom and Confucius Institute. Wuhan University Journal (Philosophy \& Social Sciences), 65(3), 22-28.

Hartig, F. (2012). Confucius Institutes and the rise of China. Journal of Chinese Political Science/Association of Chinese Political Studies, 17, 53-76.

HE, L. (2015). "Relational rationality" and real "Community". Social Sciences in China, 6, 22-44.

LIEN, D. (2011). Confucius institute effects on China's trade and FDI: Isn't it delightful when folks afar study Hanyu? International Review of Economics and Finance, 21, 147-155.

LIEN, D. (2013). Does the Confucius Institute impact international travel to China? A panel data analysis. The University of Texas at San Antonio, College of Business, Working Paper Series. 2013-02-27.

MA, G. X., \& LIU, Q. (2016). Intimacy trap and risk management: A discussion based on the paradigm of relational rationality. Thinking, 42(2), 53-58.

Morgan, J. (2009). Europe and China: A new era of cultural contact and cooperation in education. European Journal of Education, 44(1), 5-8.

New York Times. (2012). Critics worry about influence of Chinese Institutes on U. S. Campuses. Retrieved from http://www.nytimes.com/2012/03/05/us/critics-worry-about-influence-of-chinese-institutes-on-us-campuses.html?_r=1\&pag ewanted=all

PAN, S. Y. (2013). Confucius Institute project: China's cultural diplomacy and soft power projection. Asian Education and Development Studies, 2(1), 22-33.

Paradise, J. F. (2009). China and international harmony: The role of Confucius Institutes in bolstering Beijing soft power. Asian Survey, 49(4), 647-669.

Pratt, G. (1999). Geographies of identity and difference: Marking boundaries. In D. Massey, J. Allen, \& P. Sarre (Eds.), Human Geography Today. Malden, MA: Blackwell.

Starr, D. (2009). Chinese language education in Europe: The Confucius Institutes. European Journal of Education, 44(1), 65-82.

Van Campenhoudt, L. (1999). Commentary the relational rationality of risk and uncertainty reducing processes explaining HIV risk-related sexual behaviour. Culture Health \& Sexuality, 1(2), 181-191.

WU, Y. (2012). On the international communication effects of Chinese culture: Survey of 16 Confucius Institutes in 5 countries. Zhejiang Social Science, 4, 144-151.

WU, Y. H. (2011). On the index system of Confucius Institute assessment. Education Research, 8, 30-39.

ZHAO, T. Y. (2010). The ontology of coexistence from cogito to facio. Diogenes, 57, 27-36.

ZHAO, T. Y. (2015). Redefining the concept of the political with Tianxia: Its questions, conditions and methodology. World Economics and Politics, 6, 4-22. 